\title{
Ventricular late potentials measured by signal-averaged electrocardiogram in young professional soccer players
}

\author{
Jung Myung Lee* ${ }^{*}$, Hyemoon Chung, Hyung-Oh Kim, Jong-Shin Woo, Soo Joong Kim, Weon Kim,
} Woo Shik Kim and Jin-Bae Kim*

\begin{abstract}
Background and objectives: Athlete's heart is characterized by structural cardiac changes, including enlargement and hypertrophy. However, exercise-induced cardiac electrical remodeling is not well known in Asian athletes. We sought to evaluate the association between vigorous exercise and the development of abnormal late potential on signal-averaged electrocardiogram (SAECG).

Method: We analyzed 48 Korean professional soccer players and 71 healthy sedentary controls who underwent SAECG and transthoracic echocardiography at Kyung Hee University Hospital. An SAECG was considered abnormal (positive for ventricular late potential) when any one of the three following criteria was met: filtered QRS duration $>114 \mathrm{~ms}$, root-mean-square voltage in the terminal $40 \mathrm{~ms}<20 \mathrm{uV}$, or a voltage $<40 \mathrm{uV}$ for more than $38 \mathrm{~ms}$.

Results: Fragmented QRS was more commonly found in athletes (1.4\% vs. 10.4\%). Athletes demonstrated significantly higher proportion of filtered QRS duration $>114 \mathrm{~ms}(7.0 \% \mathrm{vs} .22 .9 \%, P=0.013)$ and lower terminal QRS rootmean-square voltage $<20$ uV (5.6\% vs. $20.8 \%, P=0.012)$. Ventricular late potential on SAECG was significantly more frequent in athletes (15.5\% vs. 35.4\%, $P=0.012)$. Regarding echocardiographic parameters, the athletes had larger cardiac chamber size; however, these differences became non-significant after adjustment for body surface area, except left ventricular mass index $\left(65.7 \pm 12.7 \mathrm{~g} / \mathrm{m}^{2}\right.$ vs. $\left.84.7 \pm 17.7 \mathrm{~g} / \mathrm{m}^{2}, P<0.001\right)$.

Conclusion: Abnormal SAECG findings were significantly more common in athletes than in controls. Further study is needed to determine the clinical impact of these abnormal SAECGs in athletes and cardiac outcomes in the long term.
\end{abstract}

Keywords: Electrocardiography, Athlete's heart syndrome, Signal-averaged electrocardiography

\section{Introduction}

Exercise is an important way to improve health and has been associated with a decreased risk of coronary heart disease and death [1,2]. Endurance exercise causes structural changes in the heart, which are normal physiological changes that improve cardiac performance. However, vigorous exercise may be associated with the risk of fatal

*Correspondence: cardioljm@khu.ac.kr; jinbbai@khu.ac.kr Division of Cardiology, Kyung Hee University Medical College, 23 Kyung Hee Dae-ro, Dongdaemun-gu, Seoul, Republic of Korea arrhythmia and sudden cardiac death [3]. Differentiating between these physiological changes and pathologic changes or early manifestations of cardiomyopathies is difficult. Although rare, sudden cardiac death in professional athletes has a large social impact on the community. The reports on outcomes of cardiac screening in young soccer players published in Europe suggested that electrocardiogram (ECG) and echocardiography may not be sensitive enough to detect early disease in some adolescents [4]. Several consensuses have been published for Europeans and Americans regarding cardiac screening in

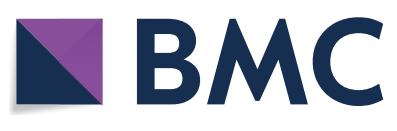

(c) The Author(s) 2021. This article is licensed under a Creative Commons Attribution 4.0 International License, which permits use, sharing, adaptation, distribution and reproduction in any medium or format, as long as you give appropriate credit to the original author(s) and the source, provide a link to the Creative Commons licence, and indicate if changes were made. The images or other third party material in this article are included in the article's Creative Commons licence, unless indicated otherwise in a credit line to the material. If material is not included in the article's Creative Commons licence and your intended use is not permitted by statutory regulation or exceeds the permitted use, you will need to obtain permission directly from the copyright holder. To view a copy of this licence, visit http://creativeco mmons.org/licenses/by/4.0/. 
athletes [5]. However, at what time and by what means should the athletes, especially Asians be screened, is highly disputed.

The signal averaged ECG (SAECG) technique is commonly used to improve the resolution of ECG to record low-amplitude electrical activity in the myocardium [6]. A delay in myocardial depolarization usually forms lowamplitude, high-frequency waveforms at the end of the QRS complex in SAECG. This delayed small fragmented potential is known as ventricular late potential (VLP) and is considered an electrophysiological substrate for ventricular arrhythmias [7]. VLP has been extensively studied in patients with myocardial infarction and independently predicted adverse outcomes and the risk of ventricular arrhythmia [8]. However, the incidence and clinical impact of VLP in professional athletes are not well understood. The aim of this study was to elucidate the electrocardiographic and clinical characteristics of professional high-dynamic low-static soccer athletes compared to sedentary healthy controls.

\section{Method}

\section{Study subjects}

We enrolled 57 Korean professional soccer players (Member of Korea Pro-Footballer's Association) who underwent SAECG and transthoracic echocardiography at Kyung Hee University Hospital. To determine the incidence of abnormal SAECG in young athletes and compare them with healthy control subjects, 72 young age controls were recruited. Control groups were apparently healthy people without active disease requiring therapy at the time of enrollment, and who do vigorous exercise less than once per week. Vigorous exercise was defined by an aerobic activity in which a conversation cannot be maintained uninterrupted [9].

According to the 2010 task force criteria for SAECG, of the 129 enrolled subjects, patients with QRS $>110 \mathrm{~ms}$ were excluded (nine athletes and one control subject), and 119 subjects (48 athletes, 71 controls) were finally analyzed [10]. All subjects underwent transthoracic echocardiography, 12-lead ECG, and SAECG. Resting 12-lead ECGs (filter range, $0.15-100 \mathrm{~Hz}$; AC filter, $60 \mathrm{~Hz}$ ) were recorded at a paper speed of $25 \mathrm{~mm} / \mathrm{s}$ and calibration of $1 \mathrm{mV} / 10 \mathrm{~mm}$. Abnormal ECG parameters in athletes were analyzed according to the Seattle criteria [11, 12]. Fragmented QRS was defined as the presence of an additional $R$ wave $\left(R^{\prime}\right)$ or notching in the nadir of the $R$ wave or $\mathrm{S}$ wave, or the presence of $>1 \mathrm{R}^{\prime}$ (fragmentation) in two contiguous leads, corresponding to a myocardial territory. The study protocol adhered to the Declaration of Helsinki and was approved by the institutional review board (2016-08-007).

\section{Signal-averaged electrocardiogram}

A MAC 5500 HD system (Version 10B, GE Healthcare system, Milwaukee, WI, USA) was used for data acquisition and analysis. After a standard 12-lead ECG was performed, the SAECG used three orthogonal bipolar leads, $\mathrm{X}, \mathrm{Y}$, and $\mathrm{Z}$ arrangements with a filter setting of $40-250 \mathrm{~Hz}$. The averaging of 200 to 400 QRS complexes with the same morphology was performed to record an SAECG with a noise level of $<0.5 \mathrm{uV}$. An SAECG was considered abnormal (Fig. 1) when any one of the three following criteria was met: (1) filtered QRS $>114 \mathrm{~ms}$; (2) root-mean-square voltage $<20 \mathrm{uV}$ in the terminal $40 \mathrm{~ms}$; and (3) a voltage $<40 \mathrm{uV}$ for more than $38 \mathrm{~ms}$, according to the criteria suggested by the Task Force Committee of the European Society of Cardiology, American Heart Association, and American College of Cardiology [10].

\section{Transthoracic echocardiography}

All study subjects underwent transthoracic echocardiography (Vivid 7, GE Vingmed Ultrasound, Horten, Norway). The left ventricular wall thickness was measured during end-diastole phases. All measurements were performed according to the current guidelines [13]. The

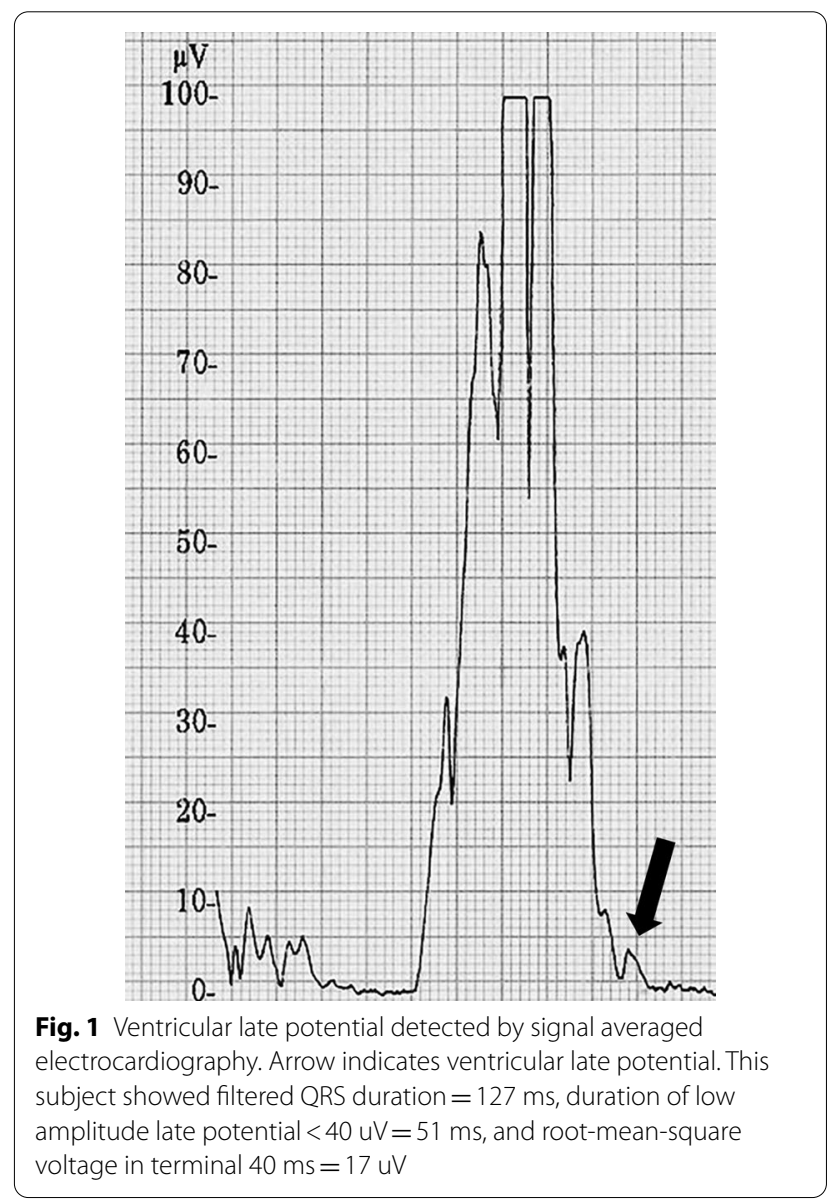


modified Simpson's rule was used to calculate left ventricular (LV) volumes and ejection fraction from apical two- and four-chamber views. The volumetric method was used to calculate LA volume from the apical fourchamber and two-chamber views at ventricular endsystole, and then, the LA volumes were indexed to the body surface area (BSA). Peak early (E) and late (A) diastolic mitral inflow velocities were measured in the apical four-chamber view. Tissue Doppler interrogation was performed in the septal mitral annulus in the apical fourchamber view, following which the peak systolic mitral annulus velocity and early diastolic mitral annulus peak velocity $\left(e^{\prime}\right)$ were measured, and ratio of $E / e^{\prime}$ was calculated. Pulsed Doppler and pulsed tissue Doppler parameters were measured as the average of three cardiac cycles.

\section{Statistical analysis}

Continuous variables were summarized as the mean \pm standard deviation and were compared using the Student's $t$ test or Mann-Whitney test wherever appropriate. Categorical variables were summarized as a percentage of the group total and were compared using Chi-squared tests or Fisher exact tests, where appropriate. A two-sided $P<0.05$ was considered to indicate statistical significance. The statistical analyses were performed using $\mathrm{R}$ software version 3.5.2. (R Foundation for Statistical Computing, Vienna, Austria).

\section{Results}

\section{Study population and echocardiography data}

The demographic and echocardiographic data of athletes and controls are presented in Table 1. None of the study population reported any symptoms suggestive of cardiovascular disease. Athletes were younger than controls $(26.0 \pm 2.1$ years vs. $20.9 \pm 3.9$ years, $P<0.001)$. Athletes were taller and had larger BSA $\left(1.65 \pm 0.2 \mathrm{~m}^{2}\right.$ vs. $\left.1.80 \pm 0.2 \mathrm{~m}^{2}, P=0.004\right)$ with no significant difference in body mass index. Both groups showed similar systolic blood pressure (SBP); however, the athletes showed significantly lower diastolic blood pressure and resting heart rate at the time of echocardiography. In echocardiographic parameters, the athletes had larger left ventricular end-diastolic diameter (LVEDD), left ventricular end-systolic diameter (LVESD), right atrium (RV) diameter, and RA area. These differences became non-significant after adjustment for BSA, except LV mass index $\left(65.7 \pm 12.7 \mathrm{~g} / \mathrm{m}^{2}\right.$ vs. $\left.84.7 \pm 17.7 \mathrm{~g} / \mathrm{m}^{2}, P<0.001\right)$.

\section{ECG and SAECG parameters}

Electrocardiographic parameters are shown in Table 2. Athletes showed lower resting heart rate $(68.1 \pm 9.3$ beats per minute $[\mathrm{bpm}]$ vs. $55.5 \pm 7.2 \mathrm{bpm}, P<0.001)$ and longer QTc interval $(413.4 \pm 23.5 \mathrm{~ms}$ vs. $436.6 \pm 27.9 \mathrm{~ms}$,
Table 1 Comparison of demographics and echocardiographic parameters between athletes and controls

\begin{tabular}{|c|c|c|c|}
\hline & Controls $(n=71)$ & Athletes $(n=48)$ & $P$ value \\
\hline Age, year & $26.0 \pm 2.1$ & $20.9 \pm 3.9$ & $<0.001$ \\
\hline Female & $27(38.0)$ & 19 (39.6) & 0.864 \\
\hline Weight, kg & $58.6 \pm 9.8$ & $64.2 \pm 14.8$ & 0.064 \\
\hline Height, cm & $165.9 \pm 8.0$ & $172.8 \pm 11.4$ & 0.004 \\
\hline$B S A, m^{2}$ & $1.65 \pm 0.2$ & $1.80 \pm 0.2$ & 0.004 \\
\hline $\mathrm{BMI}, \mathrm{kg} / \mathrm{m}^{2}$ & $21.2 \pm 2.5$ & $21.2 \pm 2.2$ & 0.973 \\
\hline $\mathrm{SBP}, \mathrm{mmHg}$ & $115.4 \pm 10.3$ & $115.8 \pm 8.7$ & 0.838 \\
\hline $\mathrm{DBP}, \mathrm{mmHg}$ & $69.3 \pm 8.7$ & $61.0 \pm 5.4$ & $<0.001$ \\
\hline $\mathrm{HR}$, beats per minute & $68.8 \pm 9.4$ & $56.9 \pm 6.6$ & $<0.001$ \\
\hline \multicolumn{4}{|l|}{ Echocardiography } \\
\hline LVEDD, mm & $46.9 \pm 3.4$ & $50.7 \pm 4.2$ & $<0.001$ \\
\hline LVEDD/BSA, mm/m² & $28.7 \pm 2.3$ & $28.6 \pm 2.3$ & 0.943 \\
\hline LVESD, mm & $29.6 \pm 2.7$ & $32.4 \pm 3.9$ & $<0.001$ \\
\hline LVESD/BSA, mm/m² & $18.1 \pm 1.7$ & $18.3 \pm 1.8$ & 0.557 \\
\hline$E F, \%$ & $61.0 \pm 4.0$ & $63.7 \pm 4.2$ & 0.003 \\
\hline LVMI, g/m² & $65.7 \pm 12.7$ & $84.7 \pm 17.7$ & $<0.001$ \\
\hline $\mathrm{LVH}^{*}$ & $1(1.4 \%)$ & $7(14.6 \%)$ & 0.007 \\
\hline LA AP diameter, mm & $31.1 \pm 3.1$ & $34.1 \pm 3.8$ & $<0.001$ \\
\hline LAV, ml & $40.6 \pm 9.6$ & $42.6 \pm 10.9$ & 0.337 \\
\hline $\mathrm{LAVI}, \mathrm{ml} / \mathrm{m}^{2}$ & $24.6 \pm 4.9$ & $23.1 \pm 4.5$ & 0.134 \\
\hline $\begin{array}{l}\text { LA enlargement clas- } \\
\text { sification }\end{array}$ & & & 0.403 \\
\hline $\begin{array}{l}\text { Normal }(L A V I \leq 34 \mathrm{ml} / \\
\left.\mathrm{m}^{2}\right)\end{array}$ & 71 & 47 (97.9\%) & \\
\hline $\begin{array}{l}\text { Mild LAE (LAVI> } 34 \mathrm{ml} / \\
\left.\mathrm{m}^{2}\right)\end{array}$ & 0 & $1(2.1 \%)$ & \\
\hline $\mathrm{E}, \mathrm{m} / \mathrm{s}$ & $0.84 \pm 0.16$ & $0.85 \pm 0.15$ & 0.853 \\
\hline $\mathrm{A}, \mathrm{m} / \mathrm{s}$ & $0.45 \pm 0.09$ & $0.34 \pm 0.08$ & $<0.001$ \\
\hline $\mathrm{E}^{\prime}, \mathrm{cm} / \mathrm{s}$ & $13.0 \pm 2.0$ & $12.4 \pm 1.8$ & 0.160 \\
\hline$A^{\prime}, \mathrm{cm} / \mathrm{s}$ & $7.2 \pm 1.5$ & $5.4 \pm 1.0$ & $<0.001$ \\
\hline$E / E^{\prime}$ & $6.6 \pm 1.3$ & $6.9 \pm 1.3$ & 0.235 \\
\hline RVD base, $\mathrm{mm}$ & $34.1 \pm 3.6$ & $37.1 \pm 3.2$ & $<0.001$ \\
\hline RVD base/BSA, $\mathrm{mm} / \mathrm{m}^{2}$ & $20.8 \pm 2.3$ & $20.8 \pm 1.9$ & 0.968 \\
\hline RVD mid, mm & $27.3 \pm 3.2$ & $28.7 \pm 2.8$ & 0.041 \\
\hline $\mathrm{RVD} \mathrm{mid} / \mathrm{BSA}, \mathrm{mm} / \mathrm{m}^{2}$ & $16.7 \pm 2.2$ & $16.1 \pm 2.4$ & 0.212 \\
\hline RVFAC, \% & $46.6 \pm 6.0$ & $47.3 \pm 6.3$ & 0.583 \\
\hline TAPSE, mm & $22.3 \pm 2.7$ & $23.7 \pm 3.7$ & 0.050 \\
\hline RA area, $\mathrm{cm}^{2}$ & $12.4 \pm 2.3$ & $14.1 \pm 2.6$ & 0.001 \\
\hline $\mathrm{RA}$ area/BSA, $\mathrm{cm}^{2} / \mathrm{m}^{2}$ & $7.6 \pm 1.2$ & $7.9 \pm 1.3$ & 0.262 \\
\hline
\end{tabular}

$A$, mitral late diastolic inflow velocity; $A^{\prime}$, mitral late diastolic tissue velocity; BMI, body mass index; $B S A$, body surface area; $D B P$, diastolic blood pressure; $E$, mitral early diastolic inflow velocity; $E$ ', mitral early diastolic tissue velocity; $E F$, ejection fraction; $H R$, heart rate; $L A E$, left atrial enlargement; $L A V$, left atrial volume; $L A V I$, left atrial volume index; LVEDD, left ventricular end-diastolic diameter; LVESD, left ventricular end-systolic diameter; LVMI, left ventricular mass index; RA, right atrium; RVD, right ventricular diameter; RVFAC, right ventricular fractional area change; TAPSE, tricuspid annular peak systolic excursion

Defined as LVMI $>95 \mathrm{~g} / \mathrm{m}^{2}$ in female, and LVMI $>115 \mathrm{~g} / \mathrm{m}^{2}$ in male 
Table 2 Comparison of electrogram and signal-averaged electrogram parameters between athletes and controls

\begin{tabular}{|c|c|c|c|}
\hline ECG parameters & Controls $(n=71)$ & Athletes $(n=48)$ & $P$ value \\
\hline Heart rate, bpm & $68.1 \pm 9.3$ & $55.5 \pm 7.2$ & $<0.001$ \\
\hline PR interval, ms & $157.9 \pm 16.5$ & $162.9 \pm 33.6$ & 0.348 \\
\hline QRS duration, ms & $90.9 \pm 8.7$ & $92.5 \pm 11.0$ & 0.379 \\
\hline QTc, ms & $413.4 \pm 23.5$ & $436.6 \pm 27.9$ & $<0.001$ \\
\hline R axis, degree & $71.3 \pm 26.1$ & $84.1 \pm 11.8$ & $<0.001$ \\
\hline T axis, degree & $51.9 \pm 12.1$ & $51.9 \pm 22.2$ & 0.992 \\
\hline Right atrial enlargement & 0 & $1(2.1)$ & 0.403 \\
\hline Q wave & $1(1.4)$ & 0 & 1.0 \\
\hline T inversion & 0 & $1(2.1)$ & 0.403 \\
\hline Early repolarization & $8(11.3)$ & $24(50.0)$ & $<0.001$ \\
\hline Fragmented QRS & $1(1.4)$ & $5(10.4 \%)$ & 0.039 \\
\hline fQRS inferior & $1(1.4)$ & $3(6.2)$ & 0.302 \\
\hline fQRS anterior & 0 & $2(4.2)$ & 0.161 \\
\hline Sinus arrhythmia & $1(1.4)$ & $7(14.6)$ & 0.007 \\
\hline \multicolumn{4}{|l|}{ SAECG parameters } \\
\hline Filtered QRS duration, ms & $102.0 \pm 11.5$ & $105.4 \pm 34.8$ & 0.544 \\
\hline Terminal QRS RMS voltage, uV & $66.4 \pm 45.4$ & $88.4 \pm 57.7$ & 0.059 \\
\hline Low amplitude late potential duration, ms & $25.1 \pm 11.1$ & $19.3 \pm 16.8$ & 0.059 \\
\hline Filtered QRS > $114 \mathrm{~ms}$ & $5(7.0)$ & $11(22.9)$ & 0.013 \\
\hline Terminal QRS RMS voltage $<20 \mathrm{uV}$ & $4(5.6)$ & $10(20.8)$ & 0.012 \\
\hline Low amplitude late potential duration $>38 \mathrm{~ms}$ & $6(8.5)$ & $4(8.3)$ & 1.0 \\
\hline 1 positive criteria & $11(15.5)$ & $17(35.4)$ & 0.012 \\
\hline 2 positive criteria & $3(4.2)$ & $4(8.3)$ & 0.438 \\
\hline 3 positive criteria & $1(1.4)$ & $4(8.3)$ & 0.156 \\
\hline
\end{tabular}

RMS, root mean square; SAECG, signal-averaged electrocardiography

$P<0.001)$ in resting ECG. Early repolarization pattern was found in half of the athletes $(11.3 \%$ vs. $50.0 \%$, $P<0.001)$. Fragmented QRS was also more frequent in athletes ( $1.4 \%$ vs. $10.4 \%, P=0.039)$. Bundle branch block pattern, premature atrial complex, or premature ventricular complex were not seen in the ECGs of all subjects. None of the ECG criteria of arrhythmogenic right ventricular cardiomyopathy (ARVC) such as Epsilon waves or localized prolongation (>110 ms) of the QRS complex in right precordial leads $\left(\mathrm{V}_{1}\right.$ to $\left.\mathrm{V}_{3}\right)$ were observed in the study subjects. SAECG parameters were compared between the two groups (Table 2). As a continuous variable, filtered QRS duration, terminal QRS root-meansquare (RMS) voltage, and low-amplitude late potential duration were not significantly different between the two groups (Fig. 2). However, when analyzed by the 2010 task force criteria for VLPs, the athletes demonstrated a significantly higher proportion of long-filtered QRS duration $>114 \mathrm{~ms}(7.0 \%$ vs. $22.9 \%, P=0.013)$ and lower terminal QRS RMS voltage $<20 \mathrm{uV}(5.6 \%$ vs. $20.8 \%$, $P=0.012$, Fig. 2). Overall, one or more abnormal SAECG findings were significantly more frequent in athletes (15.5\% vs. $35.4 \%, P=0.012$, Fig. 3 ).

\section{Regression, correlation, and sensitivity analysis}

Logistic regression analysis showed that the athletes had a higher odds ratio (OR) for the presence of VLPs $(\mathrm{OR}=2.99$, 95\% confidence interval 1.25-7.17, $P=0.014$, Table 3) than the controls. QTc interval was also associated with the presence of VLPs $(O R=1.03$ per ms, 95\% confidence interval $1.01-1.04, P=0.005)$. In the multivariate logistic regression analysis (Additional file 1 : Table S1), LVEF was the only significant predictor of VLPs. This result might be explained by a small intergroup difference but significant higher LVEF in athletes group. Although the goodness-of-fit test and variance inflation factor did not demonstrate significant problem in goodness of fit, or multi-collinearity, the possibility still remained, especially due to the small sample size.

Correlation analysis showed a significant correlation between LV posterior wall thickness and filtered QRS duration $(r=0.254, P=0.033)$. Relative wall thickness showed a trend of correlation with filtered QRS duration $(r=0.225, P=0.059)$.

For sensitivity analysis, when we excluded the patients with fragmented QRS $(n=6)$, the athletes still showed significant relationship with VLPs $(34.9 \%$ 

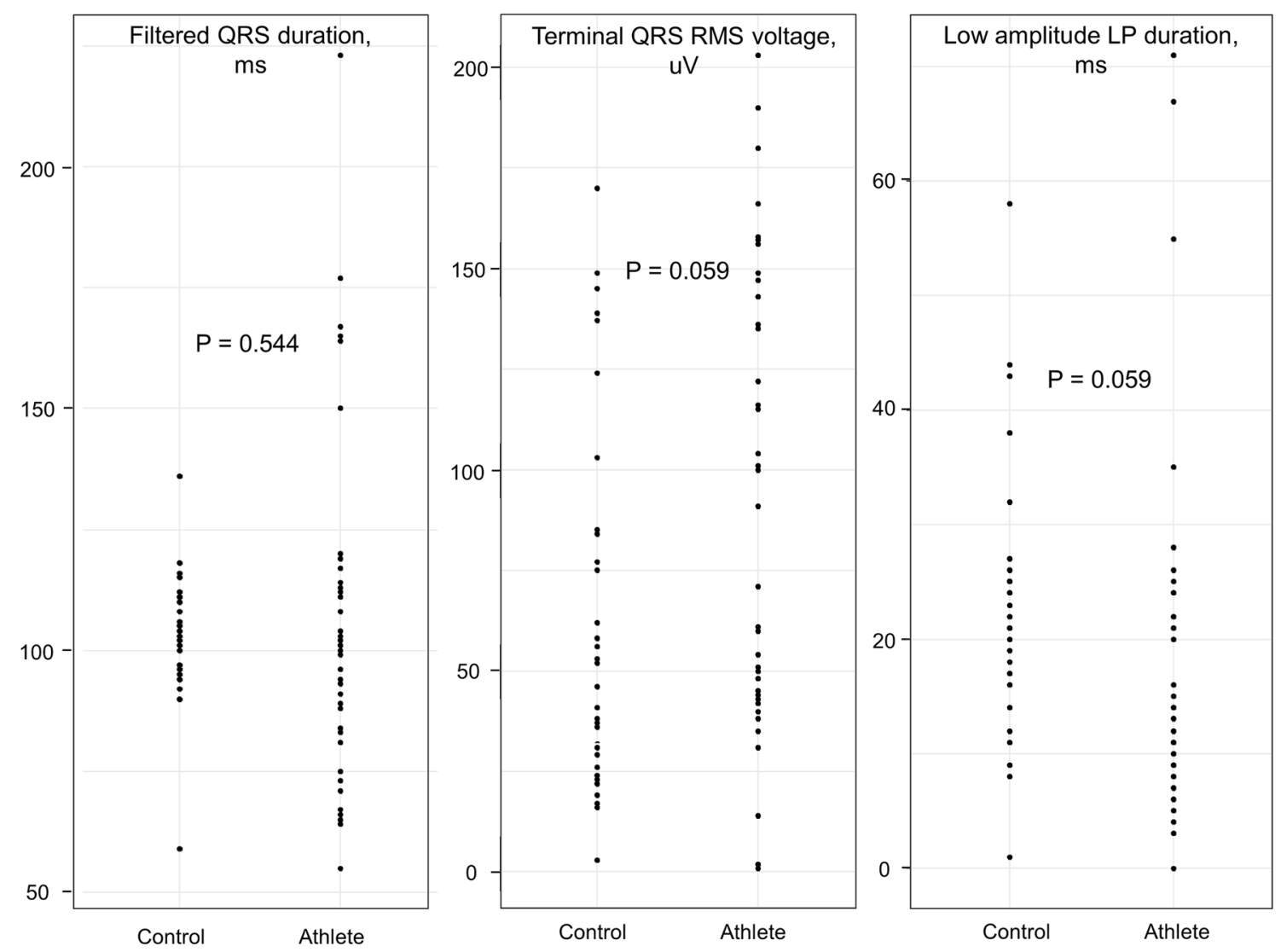

Fig. 2 Comparison of each signal-averaged electrocardiographic parameters between professional athletes and controls

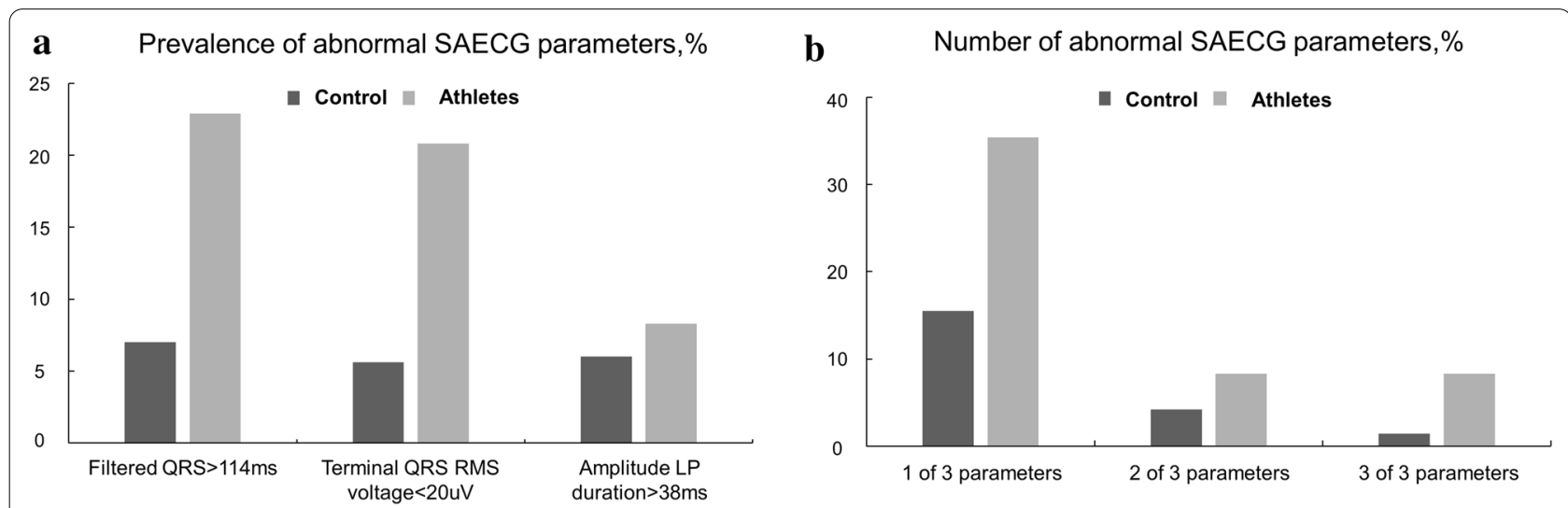

Fig. 3 Prevalence of abnormal signal-averaged electrocardiographic parameter for ventricular late potentials (VLP) in study subjects. A) Prevalence of each VLP criterion. B) Comparison of number of positive VLP criteria

vs $15.7 \%, P=0.019)$. When we excluded the patients with early repolarization $(n=32)$, the athletes showed trend for higher proportion of VLPs $(33.3 \%$ vs $15.9 \%$, $P=0.084$ ). The loss of statistical significance is presumed to be related to small sample size of our data.

\section{Discussion}

Main findings

Abnormal VLPs were more commonly found in professional high-dynamic low-static athletes than in the healthy controls. Cardiac chamber dimensions were 
Table 3 Binary logistic regression analysis of factors associated with the presence of ventricular late potentials

\begin{tabular}{llll}
\hline & Odds ratio & $\begin{array}{l}\text { 95\% confidence } \\
\text { interval }\end{array}$ & P-value \\
\hline Athletes & 2.99 & $1.25-7.17$ & 0.014 \\
Female & 1.63 & $0.74-3.60$ & 0.225 \\
Age & 0.93 & $0.82-1.05$ & 0.221 \\
Heart rate, bpm & 0.99 & $0.95-1.02$ & 0.476 \\
PR interval, ms & 1.0 & $0.98-1.01$ & 0.743 \\
QRS duration, ms & 1.04 & $0.99-1.09$ & 0.139 \\
QTc, ms & 1.03 & $1.01-1.04$ & 0.005 \\
Raxis, degree & 1.03 & $1.00-1.05$ & 0.051 \\
Taxis, degree & 1.0 & $0.98-1.02$ & 0.956 \\
Early repolarization & 1.94 & $0.86-4.41$ & 0.112 \\
Fragmented QRS & 1.67 & $0.38-7.38$ & 0.500 \\
Echocardiography & & & \\
LVEDD, mm & 0.96 & $0.80-1.16$ & 0.664 \\
LVESD, mm & 0.93 & $0.76-1.15$ & 0.506 \\
EF, \% & 1.21 & $1.06-1.36$ & 0.003 \\
LVMI, g/m ${ }^{2}$ & 1.0 & $0.98-1.03$ & 0.861 \\
RVD base, mm & 1.02 & $0.90-1.15$ & 0.765 \\
RVD mid, mm & 0.98 & $0.85-1.13$ & 0.771 \\
LAVI, mL/m ${ }^{2}$ & 0.96 & $0.84-1.08$ & 0.469 \\
RA area, cm ${ }^{2}$ & 0.89 & $0.73-1.08$ & 0.222 \\
\hline EF, ection fraction & & & \\
\hline
\end{tabular}

$E F$, ejection fraction; LAVI, left atrial volume index; LVEDD, left ventricular end-diastolic diameter; LVESD, left ventricular end-systolic diameter; LVMI, left ventricular mass index; RA, right atrium; RVD, right ventricular diameter

larger in the athletes than in the controls; however, the differences became non-significant after adjustment for BSA.

\section{Prevalence and clinical significance of late potentials}

VLP was previously reported in up to half of patients with coronary artery disease (CAD) $[7,14]$. VLP is considered an electrophysiological substrate for delayed activation of the ventricular myocardium and subsequent ventricular tachyarrhythmias. VLP has been extensively studied for risk stratification of patients with myocardial infarction and independently predicted adverse outcomes. Although most studies have been conducted in patients with CAD, some reports have suggested an increased prevalence of VLPs in non-ischemic heart failure $[15,16]$, ventricular tachycardia unrelated to myocardial ischemia [17], cardiac syndrome X [18], Brugada syndrome [19], and ARVC [20]. Recently, SAECG findings have also been suggested to be useful for the early detection of cardiac sarcoidosis [21]. VLPs were found in $11 \%$ of 79 elite handicapped athletes [22]. The prevalence of VLPs may vary according to the classification of exercise. Although VLPs were found to be as high as $100 \%$ in professional high dynamic high static athletes, their prevalence was lower in low-static athletes [23-25]. In our study, abnormal VLPs were more prevalent in athletes than in control group subjects.

The clinical impact of VLPs in athletes with normal cardiac structures is poorly understood, and there is no large long-term follow-up data regarding this issue. Recent study suggested that screening by echocardiography and 12-lead ECG during late adolescence will fail to detect a substantial proportion of athletes with or those who would eventually have a cardiomyopathy, either because the disease has not yet manifested or because ECG and echocardiography are not sufficiently sensitive to detect early disease in some adolescents [4]. Further study is needed to evaluate whether SAECG has any incremental diagnostic benefit in this population as it is less expensive than echocardiography with less burden on healthcare expenses on repeat examination.

\section{Difference of Echocardiographic parameters between athletes and controls}

In echocardiographic parameters, the athletes had larger LVEDD, LVESD, RV diameter, and RA area. These differences became non-significant after adjustment for BSA. However, LV mass index remained significantly heavier than controls $\left(65.7 \pm 12.7 \mathrm{~g} / \mathrm{m}^{2}\right.$ vs. $84.7 \pm 17.7 \mathrm{~g} /$ $\left.\mathrm{m}^{2}, P<0.001\right)$. Although LVEF was significantly higher in athletes compared with control group, LVEF values of both groups were within normal range $(61.0 \pm 4.0 \%$ vs. $63.7 \pm 4.2 \%)$, and the mean difference was only $2-3 \%$. This difference is not clinically significant. In a previous study of post-MI patients, LVEF was significantly lower in the VLP-positive group [26]. In that study, the medial difference in $\mathrm{EF}$ values between the positive and negative VLP groups was 3\%, similar to our study. In our study, it is unclear whether the small difference in LVEF is an incidental finding or has clinical meaning considering that the LVEF of entire subjects is normal. The A and $A^{\prime}$ waves were significantly lower in athletes. $A^{\prime}$ is validated as an LA functional parameter [27]. In athletes, the $A^{\prime}$ value was significantly smaller, with decreased LA function compared to the control group. The LVMI was significantly larger in athletes, and possibly, this LV geometry contributed to the difference in LA function, although there were no LA strain data in this population.

Previous studies reported that athletes' cardiac remodeling might be a physiological response to the hemodynamic demands of increased cardiac output during effort [28]. However, a recent paper reported that $17 \%$ of competitive male triathletes showed LGE by cardiovascular magnetic resonance imaging (CMR), and those with LGE had a large LVMI and high peak SBP during exercise [29]. Alternatively, competitive sports events can affect myocardial remodeling due to pressure overload 
of high BP during exercise, and the athlete's heart considered benign may progress through pathologic remodeling. In our study, filtered QRS duration was correlated with posterior wall thickness of the LV and tended to be related to relative wall thickness, which reflects LV geometry. Although we could not perform characterization of myocardial tissue using CMR, structural remodeling may be related to electrical remodeling in high-dynamic lowstatic sports athletes.

\section{Limitation}

Our sample size was relatively small. We analyzed a highly selected cohort of athletes. Therefore, the generalizability of our data to other sports participants is limited. We did not perform more detailed imaging, and/or ECG monitoring such as CMR and Holter monitoring; therefore, there is a possibility that we could not fully exclude underlying subclinical cardiac pathology. Information about family history was missing. Therefore, a genetic background of heart disease, such as cardiomyopathy, could not be evaluated. Our data are cross-sectional, and follow-up of clinical outcomes will be helpful.

\section{Conclusion}

Approximately one-third of healthy elite soccer players revealed VLPs on the SAECG, which was significantly more frequent than control group. The OR for the presence of VLP was three times higher in athletes and controls. Therefore, VLPs on SAECG should be cautiously interpreted in the athletes. Further study is needed to determine the clinical impact of these abnormal SAECGs in athletes and cardiac outcomes in the long term.

\section{Supplementary Information}

The online version contains supplementary material available at https://doi. org/10.1186/s42444-021-00031-1.

Additional file 1: Table S1. Multivariate logistic regression analysis for the predictor of ventricular latepotential.

\begin{abstract}
Abbreviations
ARVC: arrhythmogenic right ventricular dysplasia; BSA: body surface area; CMR: cardiac magnetic resonance; ECG: electrocardiography; LGE: late gadolinium enhancement; LV: left ventricle; LVEDD: left ventricular end-diastolic dimension; LVESD: left ventricular end-systolic dimension; LVMI: left ventricular mass index; RMS: root mean square; RV: right ventricle; SAECG: signal-averaged electrocardiography; SBP: systolic blood pressure; VLP: ventricular late potential.
\end{abstract}

\section{Acknowledgments}

The authors are grateful for the contributions of all the investigators and Sang Ho Kim for the data management in the SAECG laboratory.

\section{Author contributions}

JM analyzed and interpreted the patient data and a major contributor in writing the manuscript. HM interpreted the data and contributed in writing the manuscript. HO, JS, SJ, W, and WS analyzed the patient data. JB supervised the interpretation of the data and the manuscript. All authors read and approved the final manuscript.

\section{Funding}

This study was supported by a grant from the Korean Heart Rhythm Society (KHRS 2016-5).

\section{Data Availability}

The datasets used and/or analyzed during the current study are available from the corresponding author on reasonable request.

Ethical Approval and Consent to participate

The study protocol adhered to the Declaration of Helsinki and was approved by the institutional review board (2016-08-007).

\section{Consent for publication}

Not applicable.

\section{Competing interests}

The authors declare that they have no competing interests.

Received: 4 November 2020 Accepted: 19 January 2021

Published online: 26 February 2021

\section{References}

1. Arem H, Moore SC, Patel A, Hartge P, de Berrington GA, Visvanathan K, et al. Leisure time physical activity and mortality: a detailed pooled analysis of the dose-response relationship. JAMA Intern Med. 2015;175(6):95967. https://doi.org/10.1001/jamainternmed.2015.0533.

2. Wen CP, Wai JP, Tsai MK, Yang YC, Cheng TY, Lee MC, et al. Minimum amount of physical activity for reduced mortality and extended life expectancy: a prospective cohort study. Lancet. 2011;378(9798):1244-53. https://doi.org/10.1016/s0140-6736(11)60749-6.

3. Albert CM, Mittleman MA, Chae CU, Lee IM, Hennekens CH, Manson JE. Triggering of sudden death from cardiac causes by vigorous exertion. N Engl J Med. 2000;343(19):1355-61. https://doi.org/10.1056/nejm200011 093431902

4. Malhotra A, Dhutia H, Finocchiaro G, Gati S, Beasley I, Clift P, et al. Outcomes of cardiac screening in adolescent soccer players. N Engl J Med. 2018;379(6):524-34. https://doi.org/10.1056/NEJMoa1714719.

5. Pelliccia A, Caselli S, Sharma S, Basso C, Bax JJ, Corrado D, et al. European Association of Preventive Cardiology (EAPC) and European Association of Cardiovascular Imaging (EACVI) joint position statement: recommendations for the indication and interpretation of cardiovascular imaging in the evaluation of the athlete's heart. Eur Heart J. 2018;39(21):1949-69. https://doi.org/10.1093/eurheartj/ehx532.

6. Gatzoulis KA, Arsenos P, Trachanas K, Dilaveris P, Antoniou C, Tsiachris D, et al. Signal-averaged electrocardiography: past, present, and future. J Arrhythm. 2018;34(3):222-9. https://doi.org/10.1002/joa3.12062.

7. Gomes JA, Cain ME, Buxton AE, Josephson ME, Lee KL, Hafley GE. Prediction of long-term outcomes by signal-averaged electrocardiography in patients with unsustained ventricular tachycardia, coronary artery disease, and left ventricular dysfunction. Circulation. 2001;104(4):436-41. https://doi.org/10.1161/hc2901.093197.

8. Farrell TG, Bashir Y, Cripps T, Malik M, Poloniecki J, Bennett ED, et al. Risk stratification for arrhythmic events in postinfarction patients based on heart rate variability, ambulatory electrocardiographic variables and the signal-averaged electrocardiogram. J Am Coll Cardiol. 1991;18(3):687-97. https://doi.org/10.1016/0735-1097(91)90791-7.

9. Norton K, Norton L, Sadgrove D. Position statement on physical activity and exercise intensity terminology. J Sci Med Sport. 2010;13(5):496-502. https://doi.org/10.1016/j.jsams.2009.09.008.

10. Marcus FI, McKenna WJ, Sherrill D, Basso C, Bauce B, Bluemke DA, et al. Diagnosis of arrhythmogenic right ventricular cardiomyopathy/ dysplasia: proposed modification of the task force criteria. Circulation. 2010;121(13):1533-41. https://doi.org/10.1161/CIRCULATIO NAHA.108.840827. 
11. Drezner JA, Ackerman MJ, Anderson J, Ashley E, Asplund CA, Baggish AL, et al. Electrocardiographic interpretation in athletes: the "Seattle criteria." Br J Sports Med. 2013;47(3):122-4. https://doi.org/10.1136/bjsports-2012092067.

12. Sharma S, Drezner JA, Baggish A, Papadakis M, Wilson MG, Prutkin JM, et al. International Recommendations for Electrocardiographic Interpretation in Athletes. J Am Coll Cardiol. 2017;69(8):1057-75. https://doi. org/10.1016/j.jacc.2017.01.015.

13. Lang RM, Badano LP, Mor-Avi V, Afilalo J, Armstrong A, Ernande L, et al. Recommendations for cardiac chamber quantification by echocardiography in adults: an update from the american society of echocardiography and the European Association of Cardiovascular Imaging. J Am Soc Echocardiogr. 2015;28(1):1-39.e14. https://doi.org/10.1016/j. echo.2014.10.003.

14. Kuchar DL, Thorburn CW, Sammel NL. Late potentials detected after myocardial infarction: natural history and prognostic significance. Circulation. 1986;74(6):1280-9. https://doi.org/10.1161/01.cir.74.6.1280.

15. Middlekauff HR, Stevenson WG, Woo MA, Moser DK, Stevenson LW. Comparison of frequency of late potentials in idiopathic dilated cardiomyopathy and ischemic cardiomyopathy with advanced congestive heart failure and their usefulness in predicting sudden death. Am J Cardiol. 1990;66(15):1113-7. https://doi.org/10.1016/0002-9149(90)90514-2.

16. Poll DS, Marchlinski FE, Falcone RA, Josephson ME, Simson MB. Abnormal signal-averaged electrocardiograms in patients with nonischemic congestive cardiomyopathy: relationship to sustained ventricular tachyarrhythmias. Circulation. 1985;72(6):1308-13. https://doi.org/10.1161/01. cir.72.6.1308

17. Coto H, Maldonado C, Palakurthy P, Flowers NC. Late potentials in normal subjects and in patients with ventricular tachycardia unrelated to myocardial infarction. Am J Cardiol. 1985;55(4):384-90. https://doi. org/10.1016/0002-9149(85)90381-9.

18. Lutfi MF. Ventricular late potential in cardiac syndrome $X$ compared to coronary artery disease. BMC Cardiovasc Disord. 2017;17(1):35. https:// doi.org/10.1186/s12872-017-0469-6.

19. Ikeda T, Sakurada H, Sakabe K, Sakata T, Takami M, Tezuka N, et al. Assessment of noninvasive markers in identifying patients at risk in the Brugada syndrome: insight into risk stratification. J Am Coll Cardiol. 2001;37(6):1628-34. https://doi.org/10.1016/s0735-1097(01)01197-4.

20. Liao YC, Lin YJ, Chung FP, Chang SL, Lo LW, Hu YF, et al. Risk stratification of arrhythmogenic right ventricular cardiomyopathy based on signal averaged electrocardiograms. Int J Cardiol. 2014;174(3):628-33. https:// doi.org/10.1016/j.jijcard.2014.04.169.

21. Yodogawa K, Seino Y, Ohara T, Iwasaki YK, Hayashi M, Miyauchi Y, et al. Prognostic significance of ventricular late potentials in patients with pulmonary sarcoidosis. Heart rhythm. 2018;15(6):798-802. https://doi. org/10.1016/j.hrthm.2018.03.013.

22. Oliveira Filho JA, Luna Filho B, Covre SH, Lira Filho E, Regazzini M, Greco $J$, et al. Signal averaged electrocardiogram in top deficient athletes. Arq Bras Cardiol. 1999;72(6):687-92. https://doi.org/10.1590/s0066-782x1 999000600004

23. Jongman JK, Zaidi A, Muggenthaler M, Sharma S. Relationship between echocardiographic right-ventricular dimensions and signal-averaged electrocardiogram abnormalities in endurance athletes. Europace. 2015;17(9):1441-8. https://doi.org/10.1093/europace/euv063.

24. Moroe K, Kimoto K, Inoue T, Annoura M, Oku K, Arakawa K, et al. Evaluation of abnormal signal-averaged electrocardiograms in young athletes. Jpn Circ J. 1995;59(5):247-56. https://doi.org/10.1253/jcj.59.247.

25. Biffi A, Ansalone G, Verdile L, Fernando F, Caselli G, Ammirati F, et al. Ventricular arrhythmias and athlete's heart. Role of signal-averaged electrocardiography. Eur Heart J. 1996;17(4):557-63. https://doi.org/10.1093/ oxfordjournals.eurheartj.a014909.

26. Bauer A, Guzik P, Barthel P, Schneider R, Ulm K, Watanabe MA, et al. Reduced prognostic power of ventricular late potentials in post-infarction patients of the reperfusion era. Eur Heart J. 2005;26(8):755-61. https://doi. org/10.1093/eurheartj/ehi101.

27. Blume GG, McLeod CJ, Barnes ME, Seward JB, Pellikka PA, Bastiansen PM, et al. Left atrial function: physiology, assessment, and clinical implications. Eur J Echocardiogr. 2011;12(6):421-30. https://doi.org/10.1093/ejech ocard/jeq175.

28. DAndrea A, Bossone E, Radmilovic J, Caso P, Calabro R, Russo MG, , et al. The role of new echocardiographic techniques in athlete's heart. Res. 2015;4:289. https://doi.org/10.12688/f1000research.6745.1.

29. Tahir E, Starekova J, Muellerleile K, von Stritzky A, Munch J, Avanesov M, et al. Myocardial fibrosis in competitive triathletes detected by contrastenhanced CMR correlates with exercise-induced hypertension and competition history. JACC Cardiovasc Imaging. 2018;11(9):1260-70. https ://doi.org/10.1016/j.jcmg.2017.09.016.
Ready to submit your research? Choose BMC and benefit from:

- fast, convenient online submission

- thorough peer review by experienced researchers in your field

- rapid publication on acceptance

- support for research data, including large and complex data types

- gold Open Access which fosters wider collaboration and increased citations

- maximum visibility for your research: over 100M website views per year

At BMC, research is always in progress.

Learn more biomedcentral.com/submissions 